\title{
14
}

\section{Virtual Schools}

Revolution in Pedagogy and Technology

Jun Jo and Neil Russell

Griffith University, Gold Coast Campus, PMB 50 Gold Coast Mail Centre, Queensland 9726. Australia

J.Jo@mailbox.gu.edu.au

Keywords: virtual school, future, catalyst for change, learner-centred learning, pedagogy

Abstract This paper explores the question of whether 'virtual' schooling is a realistic concept and faces the challenging question of whether computers will replace teachers. A possible scenario of future school education is described, and economic, technological and social factors that might encourage or hinder such a change are considered. Recent developments in video streaming technology are reviewed and the use of video streaming technology related to the viability of virtual schools concepts. Implications are drawn for students, teachers and teacher educators relating to the concept of virtual schools.

\section{A SCENARIO OF SCHOOL EDUCATION IN 2010}

Jenny, who is 15 , attends classes at a secondary school for two days a week. This morning, she will have lessons in English, Mathematics and Japanese, and in the afternoon she will participate in sport. The morning lessons all involve networked computers. The school has purchased complete curriculum packages from a private commercial supplier, and these are delivered over the World Wide Web using real time video streaming technology. The curriculum package is directly related to the State Education Department outcomes based syllabus. Completed work is sent electronically to a computer service supply company, and forwarded to casual 'fee for service' tutors in the State capital for assessment and return. Work will be assessed in terms of outcomes achieved. 
For the other three days of the week, Jenny works from home. The school has offered a computer-based curriculum program to students in exchange for discounted school fees, and Jenny's mother has arranged her part-time work so that she can monitor her daughter's work. An inexpensive internetcapable computer with a desktop video-conferencing camera enables Jenny to complete her schoolwork without leaving the house. Jenny receives lessons prepared and presented by experienced teachers using videostreaming technology.

\section{PREDICTING WAYS COMPUTERS WILL BE USED}

Attempts to predict the ways in which computers will be used in the future have been notoriously bad, as Denning and Metcalfe (1997) point out. In the application of computers to education, it is likely that those who in an earlier era considered the question of whether computers could replace teachers did so when the connectivity of the 21 st century was as yet undeveloped. In the pre-World Wide Web era of the 1980's, when computers were less common in schools and homes, it is not surprising that writers such as Hilbun (1983) and Pheasant (1989) would believe that it was unlikely that computers would replace teachers.

During the 1990's, however, as networked computers became common, two groups could be identified with opposing views. While some teachers defended their role and argued that computers could be seen as a vital component of the teaching process, some critics saw traditional school education as flawed, inefficient and dated. In this understanding of schooling, schools and teachers are seen as redundant because they belong to an inefficient industrial age. Tiffin and Rajasingham (1995) argue that schools are currently designed for an industrial society rather than one based on information, while Perelman maintains that "the classroom and the teacher have as much place in tomorrow's learning enterprise as the horse and buggy have in modern transportation." (1992, p.19). While the debate between traditional educators and their critics is necessarily constrained by the technology and the context in which they live, it is also affected by broader events over time. A historical overview of workers' opposition to machines that threatened to displace them provides a useful perspective. 


\section{IMPROVEMENTS IN THE MECHANISM: HISTORICAL ANTECEDENTS}

It is clear that there are a number of reasons why a new technology might be opposed. In the early stages, the innovation may be seen as impractical, expensive, or unsafe. However, a continuing theme is that of resistance by groups who see new technology as an economic threat to their livelihood. Sometimes, those who saw themselves as threatened ran a program which reminded the public of the disadvantages of the new technology, as the telegraph companies did in the USA when they opposed the introduction of the telephone in the early Twentieth Century (Technological Trends 1937, p. 50).

Historical precedents suggest that, in school education, arguments opposing the replacement of teachers by computers on educational grounds may mask a justifiable fear related to the loss of employment. While educators may advance convincing arguments about the poor quality of computer-delivered education, or the inability of computers to replace key human functions, the issue can be interpreted in terms of two opposing vested interest groups.

The school education sector is one of these interest groups, and it represents a significant number of people who earn their living from traditional schooling, either directly or indirectly. A change involving the replacement of some teachers with computers could mean the end of school as we know it, and in addition to teachers, groups such as clerical and maintenance workers, administrators, and textbook suppliers would have to diversify or accept changed employment conditions.

Opposed to traditional employees in education and related occupations are those who would benefit from technologies which might replace teachers. Principally, this involves those in the IT industry such as hardware and software manufacturers and retailers, providers of online services and curriculum packages, and members of the advertising and media industries.

Reappraisal of school functions, in the context of changing societal expectations, suggests that in addition to the pressures for replacement of teachers by computers, there may be significant changes to teachers' tasks. Those who continue their involvement with children's education may still be referred to as teachers, but what they do in future may be very different from those who have taught in previous eras. 


\section{REPLACEMENT, DE-SKILLING OR RE- SKILLING?}

The discourse arising from the question of teachers being replaced by computers can be seen in terms of a threat to teachers' jobs, and in changes to customary teaching practices, involving both de-skilling and re-skilling. The Luddites had seen themselves as skilled, and were proud of the quality of their work. When they were forced to change their traditional mode of textile work at home for factory life, some traditional skills were lost. Similarly, teachers' change in role from expert to facilitator (ACT Department of Education 1996) could result in the loss of traditional skills central to self-esteem and social and economic value.

Didactic teaching which follows a traditional information transmission model, or networked computers threaten the 'banking' model criticised by Friere (1995). When teachers expertise is based on their knowledge of subject matter, competition from information sources such as the World Wide Web, CD-ROMS and the availability of computers at home may mean that students no longer rely on teachers as their chief information source.

In addition to losing their status as the main providers of information, teachers can also find that the curriculum has been prescribed and provided by an educational authority, and as a consequence, their skills of curriculum design are redundant. Apple and Jungck (1998) provide an example of a computer literacy unit, which did not require a skilled teacher to teach it. The concept of a 'canned curriculum' can be traced back to at least the Sputnik era of the 1950's (Apple 1982), when perceived inadequacies in the American educational system in the Sputnik era led to a perception that teachers could not be trusted with curriculum. As a result, there was an identifiable trend in which curriculum was specified in detail, and textbooks were prescribed which limited teachers' ability to respond to students' needs.

The Internet has created a new and different culture with the 'Computer/Net' generation thinking differently to older generations. It creates the new 'Web life style' (Gates 1999), such as Internet marketing, banking, billing mortgaging, and paying accounts via a credit card. In education, the Internet has the potential to help with different learning styles.

Some people learn better by reading, some by listening, some by watching someone else do a task, some by doing the task. Most of us learn from some combination of all these methods. And all people have different levels of aptitude and different personalities and life experiences that may motivate them to learn or de-motivate them. A highly motivated student can learn from difficult reading materials, where a poorly motivated student needs accessible materials such as a video to learn. 
New software is helping students learn regardless of learning style or pace (Gates 1999, p. 399)

There is also some evidence that students learn many computer applications at home rather than at school, even though some applications are taught in regular classes. In Australia, the Real Time Report (Detya 1999) reported a survey of computer skills of 6213 students in schools across all educational sectors. Although some individual skills had been mostly learned at school, students indicated that a majority of their computer skills had been learned at home.

While computer skills are only a small part of what students are expected to learn at school, it is likely that continuing proliferation of sophisticated software, and the availability of networked computers from home will change what teachers do in classrooms. Although many teachers will remain within the instructional loop, their function will gradually become more of a manager and supervisor. There will still be discussion and assistance with students' learning, but student interaction will increasingly be with a computer rather than a teacher. Consequently, the traditional feedback between teacher and student will be reduced. Administrators who realise that different skills are now required of teachers may consider employing tutors or even using parents or volunteers to supervise the students' learning.

Yet despite concerns that the increased use of computers on schools will lead to the deskilling of teachers, there is also a strong argument in favour of their re-skilling. Students who encounter information overload from the World Wide Web will still need skilled assistance to analyse and synthesise data, and to detect bias and irrelevance. There may be more of a need for differently skilled teachers in the classroom rather than less. Calls by politicians and educators for teachers to undergo professional development in learning technology so that their pedagogy will be more appropriate for the information age reflect a continuing dissatisfaction with teaching practices.

\section{TECHNOLOGICAL CHANGE AND TEACHERS}

The possibility that computers will replace teachers is also related to the effectiveness with which computers are able to carry out teachers' tasks, although there are certainly other factors to be considered. If extrapolations of existing trends continue uninterrupted, Bell and Gray (1997) predict that by 2047 computers will be at least one hundred thousand times more powerful than they are today, and the factor may indeed be in the billions. Future students are likely to have access to a version of the World Wide 
Web, which will be used by many people as part of their everyday life. There should be few problems with accessing interactive websites with fullmotion video at home, at school, or from an internet-capable mobile phone. Those elements of teaching practice which are related to the dissemination of information, and even interactivity, is likely to be challenged with such developments as a consequence.

In addition to preparing teaching materials, teachers developing activities for students enrolled in the virtual school will need to understand and deal with various aspects of technology to prepare the computer based learning materials effectively. They will need to develop skills in:

- how to use various formats of multimedia data such as bitmap/vector graphics, 2D images/3D objects, animation/movie, and sound/music

- evaluating options to compress large amounts of data into a file of manageable size without losing its original quality

- deciding what is the best option among all the new technologies to efficiently deliver information to students seamlessly

- managing and analysing an Internet database, to observe students' progress

- tracing and analysing patterns of students' navigation methods and use of teaching materials.

Demands for this new teaching environment have implications for the content and pedagogy of teacher education programs. New approaches for preparing teachers for work in virtual schools could include majors in areas such as multimedia data management in education, Internet Technology in Education, and integrating the use of the Internet across the curriculum.

The use of IT in Education can be segmented into three major parts:

- Authoring

- Delivery of teaching materials

- Developing the Student-computer Interface.

Teachers will need to prepare teaching materials in quite different formats to traditional schooling situations. This change will need to provide students with more flexible and interactive teaching programs. (Perez and Jo 2000). This current research into the preparation of teaching materials for use in virtual schools has indicated that the time taken to prepare useful materials for students to work on is very extensive, particularly when dynamic media such as audio/video are used. In the near future, the authoring environment will become much easier to use, with educators being able to use authoring software in similar ways to the way a word processing program is used currently.

Two crucial limitations in delivering educational materials are the large size of multimedia files and the slow speed of data transmission over the 
Internet. To overcome these problems approaches are being developed to deliver multimedia information seamlessly.

In the software development area, various international compression standards in multi-media information, such as MPEG1, MPEG2, and MPEG4 have been developed. Recently a number of multimedia companies such as, Real Networks, Windows and Media Technologies and Apple QuickTime have developed various forms of audio/video streaming technology.

Another approach to improve online delivery is in the hardware area. High bandwidth equipment that is currently available includes ADSL, ISDN, Cable TV line using HFC networks and Satellites using a satellite dish. These high bandwidth options are currently expensive and not practical for most student learning applications. However, these access methods will be more readily available and cost-effective in the near future (Jones et al. 2000). Teachers in the future virtual school should possess enough understanding of the new and evolving technologies therefore, to be able to choose one or a combination of appropriate delivery methods for specific subjects or courses.

Although the User Interface (UI) seems to have evolved at a slower rate compared with the authoring and delivery aspects of the virtual learning environment, the user interface procedure is very important to provide students with efficient and realistic interactions.

One interesting development of UI is the so-called 'Intelligent Interface' Woern (1997). Intelligence in UI means that the interface software, hardware or system can understand the user's behaviours and expectation and helps guide his/her uses. One early example of intelligent interface is the 'auto correction tool' in word processing programs others include speech recognition and techniques that allow the user - system interaction to be adapted to different users.

The types of UI that are available to the students will affect the navigation patterns. Educators will need to be familiar with the new UI technologies and develop teaching materials for them.

\section{CUSTODIAL FUNCTION OF SCHOOLS: CHANGING EXPECTATIONS OF EDUCATION}

The future may see students using computers from home while their parents supervise them, but this notion runs counter to the expectation that the state or an educational authority supervises students during the day while parents earn a living elsewhere. For this reason, it is likely that the noncompulsory sector of school education, senior high school, will be among 
the first to trial off-site schooling as an alternative for students. As this mode of learning slowly gains acceptance, it will increasingly become available to other high school students whose parents are prepared to accept it, and finally to primary school students.

Although the movement from traditional classroom-based education may be initially slow, the pace is likely to be accelerated both by the models provided by higher education and the changing nature of societal understandings of schooling.

While primary schools would initially seen to be apart from such considerations, schooling will continue to be changed by their use of computers both at school and at home. The school, which is not connected to the Internet in industrialised countries, is becoming the exception. In the USA, 95\% of public schools are connected to the Internet (NCES 2000), and home access to the Internet is also increasing in many countries. As connectivity increases, schools will increasingly place homework and whole units of work on the World Wide Web, where parents can monitor their child's progress and assist with the work. Some parents who accept that networked learning is a valid learning mode may be willing to consider the next step, which is to supervise their child themselves at home.

\section{THE VIRTUAL SCHOOL AND THE LATE AGE OF TRADITIONAL SCHOOLING}

In Australia, Education Queensland has established a Virtual School concept to enable additional curriculum choice to small, rural and remote schools. (Ewing and Smith 2000). Students can log into the Virtual School via a web page on the State Education Department network and participate in both real time links to their teachers or use online delivery methods. During Virtual School classes, students can interact with teachers using voice communication, sharing documents and accessing resource materials using a Virtual school web site. As students can access the Virtual School from home as well as at school this Virtual School will become a viable option for those parents who want to home school their children. In addition, schools can consider a timetable, which may include several days a week of students working from home.

Additional examples of Virtual Schools can be located without difficulty on the World Wide Web. (Phillips 1998). As virtual schools become more common, the resulting challenge to assumptions about teachers' roles in conventional school classrooms may result in the present era being seen as the Late Age of Schooling. Teachers face turbulent times as they are forced to both re-skill and deskill, while concurrently, a modest increase in 
computer-related home schooling may lead to some teachers effectively being replaced by computers. A complex mix of economic, technological and social factors will help to determine the future shape of school education.

\section{CONCLUSION}

The concept of teaching in a virtual school may need a totally different culture to be established compared with those of a traditional school. Multimedia designers can assist teachers to develop activities for students enrolled in the virtual school, but teachers still need to understand and decide on the best options to deliver the curriculum effectively. Hence in order to prepare curriculum materials, teachers will need to understand and decide on the best options to author and deliver the curriculum effectively and the best way for students to interact with it. Fortunately, the rapid development of multimedia authoring tools will enable this aspect of a teacher's professional development to be achieved, without burying the teacher in technological detail.

We have argued in this paper that there is a need to re-skill teachers to work in virtual school settings if this concept of a virtual school is to be realised. This re-skilling will need to involve establishing benchmarks or standards in both the technology and pedagogy areas for graduating teachers if they are to contribute to the development of the virtual school.

\section{REFERENCES}

ACT Department of Education and Training and Children's Youth and family Services Bureau (1996) Gateways - Information technology in the learning process. Author, Tuggeranong.

Apple, M. W. (1982) Education and Power. Routledge \& Kegan Paul, London.

Apple, M. W. and Jungck, S. (1998) "You don't have to be a teacher to teach this unit": Teaching, Technology and Control in the Classroom. In Education/Technology/Power: Educational Computing as a Social Practice, H. Bromley and W. M. Apple (eds.), State University of New York Press, Albany, pp. 133-154.

Bell, G. and Gray, J. N. (1997) The Revolution yet to happen. In Beyond Calculation: The Next fifty Years of Computing, P. J. Denning, and R. M Metcalfe (Eds.), Springer-Verlag, New York, pp. 5-32.

Denning, R. J. and Metcalfe, R. M. (1997) Preface. In Beyond Calculation: The Next fifty Years of Computing, P. J. Denning and R. M. Metcalfe (eds.), Springer-Verlag, New York, pp. xiii-xvi. 
DETYA (1999) Real Time: Computers, Change and Schooling - National sample study of the information technology skills of Australian school students. Australian Key Centre for Cultural and Media Policy. [http://www.detya.gov.au/schools/publicat.htm] 19/01/2000.

Ewing, R. A. and Smith, D. L. (2000) Curriculum Issues Raised by Technology. Curriculum Perspectives, 20 (3), p. 65.

Freire, P. (1995) Pedagogy of the Oppressed. Continuum, New York.

Gates, B. (1999) Business@ The Speed of Thought. Viking Books, U.K.

Hilbun, J. and Maxcy, S. J. (1983) If computers can think, do we need teachers? Focus on Learning, 9 (2), pp. 40-45.

Jones, V., Cranitch, G. and Jo, J. H. (2000) Hyweb: A hybrid-web system for delivery and enhancement of web-based and traditional teaching. To appear in Proceedings of AusWeb 2001, Coffs Harbour.

Perelman. L. J, (1992) School's Out: Hyperlearning, the New Technology and the End of Education. William Morrow and Company, New York.

Perez, M. and Jo, J. H. (2000) Leaming Sequence controlled by Learners and Educators, within a CBI System. In Proceedings of CAP's3: Third International Conference on Human-Learning System, Paris.

Pheasant, M. F. W. (1989) Computers as surrogate teachers: A study of potential legal barriers in four western states. $D A I, 50$, no. $05 \mathrm{~A}, 1165$.

Phillips, V. (1998) Virtual Classrooms, real education. [http://geteducated.com/articles/genb.htm].

Technological Trends (1937) Technological Trends and National Policy, including the Social Implications of New Inventions. Report of the Subcommittee on Technology to the National Resources Committee, June 1937, United States Government Printing Office, Washington.

Tiffin, J. and Rajasingham, L. (1995) In search of the virtual class: Education in an information society. Routedge, London.

Woern, A. (1997) What is an Intelligent Interface.

[http://www.sics.se/ annika/papers/intint.html].

\section{BIOGRAPHY}

Dr Jun Jo has developed and implemented an online teaching system for one of his subjects since 1999. He is conducting the 'Intelligent Multimedia Research (IMR) Laboratory' and e-learning is one of his research interests.

Professor Neil Russell is currently researching the computing skills of very young children and the development of 'virtual' schools and universities. 